ORIGINAL RESEARCH PAPER

\title{
CHARACTERIZATION OF THREE CULTIVARS OF INDONESIAN GLUTINOUS RICE: A BASIS FOR DEVELOPING RICE-BASED FUNCTIONAL FOOD
}

\author{
WIWIT AMRINOLA ${ }^{1,2}$, AZIS BOING SITANGGANG $^{1 *}$, FERI KUSNANDAR $^{1}$, SLAMET $^{2}$ \\ BUDIJANTO $^{1}$

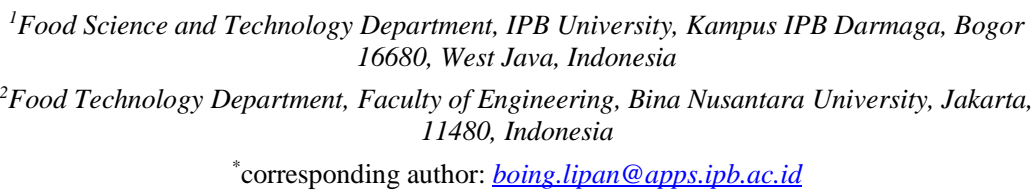

Received on 5 March 2021

Revised on 24 May 2021

\begin{abstract}
White, red and black glutinous rice are common rice cultivars used as raw materials for food products in West Sumatera, Indonesia. The characteristics of these three cultivars are different, and thus there is a need to elucidate the differences. The characterization of physicochemical and antioxidant properties of these three local cultivars was performed in this study. Three local glutinous rice paddy cultivars were milled to obtain brown glutinous rice. The results showed that black glutinous rice had higher ash content, total dietary fiber, total phenolic content, total flavonoid components, total anthocyanin content than other cultivars. Having higher phenolic, flavonoid, and anthocyanin content, the black glutinous rice consequently had higher antioxidant activity than white and red glutinous rice. Moreover, white glutinous rice had higher fat content and amylose content, and had higher starch digestibility amongst others. The highest protein content was obtained from red glutinous rice. The pasting properties, fatty acid compositions, and amino acid compositions of each glutinous rice were also determined and the results showed distinct profiles between the cultivars.
\end{abstract}

Keywords: Indonesian glutinous rice, pigmented glutinous rice, non-pigmented glutinous rice, functional food, antioxidant properties

\section{Introduction}

Rice (Oryza sativa $\mathrm{L}$ ) is considered as the most widely consumed staple food for more than $60 \%$ of the world's population, and is considered the main staple food for Indonesian people. Rice is a major source of nutrients, consisting of carbohydrates,

https://doi.org/10.35219/foodtechnology.2021.1.10 
proteins, fats, fibers, minerals, vitamins, etc. (Chavan et al., 2017). Glutinous rice (Oryza sativa L var. glutinosa) is one of the most popular varieties of rice (Kang et al., 2010). There are three types of glutinous rice commonly consumed in West Sumatera, i.e. white, red, and black glutinous rice. The type of the cultivars is grouped based on the color or pigments found on the surface of the rice or bran layer (pericarp). This colored rice is called pigmented rice. The common pigments in red and black rice are anthocyanins (ACNs) and proanthocyanidins (PA) (Huang and Lai, 2016). They have not been characterized, and are commonly used as raw materials for food products.

As the outer part of the whole grain, the proportion of rice bran is about $6-7 \%$ by weight whereas for endosperm and embryo are 90 and 2-3\%, respectively. Rice bran is composed by both macro and micromolecules, such as lipids, dietary fibers, protein, and vitamins, minerals, $\gamma$-aminobutyric acid (GABA), and those compounds exhibiting antioxidant properties (flavonoids, phenolic acids, $\gamma$-oryzanol, tocopherols, etc.) (Chavan et al., 2017). These antioxidative compounds have been reported to have a positive influence on health especially for suppressing oxidative stress, mutagenesis, and carcinogenesis (Goufo and Trindade, 2014; Sompong et al., 2011; Thammapat et al., 2015).

Starch is the largest constituent of rice endosperm. Starch is composed of two polymers, namely amylose and amylopectin. Glutinous rice, also called waxy or sticky rice, is different from other rice types. The starch in glutinous rice has a very low amylose content (less than $2 \%$ of the starch) whereas amylopectin comprises up to $100 \%$ of the starch. The ratio of amylose-to-amylopectin has been reported to influence rice starch alkali digestibility, gel consistency, and gelatinization temperature. For regular rice, such translucent appearance is obtained. Whereas for glutinous rice, a distinct opaque whiteness is often seen. Interestingly, the appearances between regular rice and glutinous rice are switched after cooking. Hereby, the sticky rice has translucent look, while regular rice becomes opaque white. Starch with high amylopectin content will be more difficult to form a firm gel when it is cooked. The long texture properties cause a tendency to stretch and break, resulting in a greater level of development (Kang et al., 2010).

Based on the afore explanation, the purpose of this study is to characterize the physicochemical, functional, and evaluation of nutritional characteristics of glutinous rice cultivars that are widely used in West Sumatra (white, red, and black glutinous rice) which have the potential as a functional food ingredient.

\section{Materials and methods}

\section{Materials}

All cultivars of glutinous rice (white, red, and black glutinous rice) were obtained directly from local farmers in Padang Panjang and Agam Areas in West Sumatera, Indonesia. The three local glutinous rice paddy cultivars were husked to obtain brown glutinous rice, which still shows evidence of rice bran that would be used for characterization. Chemical reagents for analysis (such as Ethanol, Methanol, n- 
Hexane, HCl, Folin-Ciocalteau, etc.) were obtained from Merck (PT. Merck Tbk. Merck Groups Companies in Indonesia), while DPPH and Quarcetin were obtained from sigma-Aldrich (Sigma Chemical Co., St. Louis, USA).

\section{Determination of chemical composition}

Proximate analyses were carried out following the AOAC (2005) methods. The moisture content was determined gravimetrically using an oven at $100{ }^{\circ} \mathrm{C}$ to a constant weight (method 925.09B). The crude protein content was determined with Kjeldahl method (method 992.23) and the crude fat was determined with the Soxhlet extract method (method No. 920.39C). Ash content was determined using a muffle furnace at $550^{\circ} \mathrm{C}$ (method No. 923.03). Meanwhile, the carbohydrate content was calculated by the difference method (AOAC, 2005). The determination of amylose and amylopectin contents followed a method developed by Juliano (1971). As for dietary fiber content analysis, the method used was a modified multi-enzyme method following AACC Method 32-21.01 (AACC, 2009).

\section{Profile of pasting properties}

Pasting properties were analyzed using AACC Method 61-02.01 (AACC, 2009) method utilizing Rapid Visco Analyzer (RVA) instrument. As much as $3 \mathrm{~g}$ of the sample was weighed directly into the disposable aluminum canister. The distilled water was then added to reach a total weight of $28 \mathrm{~g}$. At first, the suspension was heated from $30^{\circ} \mathrm{C}$ until it reached a temperature of $50^{\circ} \mathrm{C}$, and was held at $50^{\circ} \mathrm{C}$ for 1 min. Then the suspension was heated again to a temperature of $95^{\circ} \mathrm{C}$ for $3.5 \mathrm{~min}$. After reaching $95^{\circ} \mathrm{C}$, the temperature was maintained for $2.5 \mathrm{~min}$ before lowering it back to $50^{\circ} \mathrm{C}$ within $3.5 \mathrm{~min}$. The parameters measured were gelatinization temperature (pasting temperature), peak viscosity, minimum viscosity / trough (T), final viscosity at $50^{\circ} \mathrm{C}$, breakdown $(\mathrm{BD}=$ peak viscosity - minimum viscosity), and set back ( $\mathrm{SB}=$ final viscosity - peak viscosity).

\section{Determination of microstructure}

Microstructure analysis was performed using a Scanning Electron Microscope (SEM) Zeiss EVOIMA 10, detector SE (secondary electron), WD (working distance) $8.0-9.0 \mathrm{~mm}$, and ETH $16.00 \mathrm{kV}$. The samples of glutinous brown rice were comminuted prior to the microstructure analysis. The prepared samples were placed on the sample holder and coated with a layer of thin gold at 60 seconds sputter time at $20 \mathrm{~mA}$.

\section{Determination of fatty acid composition}

Gas chromatography was used to measure fatty acid composition. As much of $5 \mathrm{~g}$ of sample was extracted with a chloroform-methanol mixture. This oil was used for the methylation of fatty acids. Methylation was carried out in a test tube with a lid, where $25 \pm 2 \mathrm{mg}$ of the extracted sample was added with $1.5 \mathrm{ml}$ of $\mathrm{NaOH}-\mathrm{Methanol} 0.5 \mathrm{~N}$. The mixture was thoroughly vortexed for $30 \mathrm{~s}$ and continued with $\mathrm{N}_{2}$ sparging for 1 $\min$. It was then heated at a temperature of $80-100^{\circ} \mathrm{C}$ for $5 \mathrm{~min}$ and cooled in running water. About $2 \mathrm{ml} \mathrm{BF}_{3}$ Methanol were added and vortexed for 30 seconds, blown with $\mathrm{N}_{2}$ gas, and further heated at a temperature of $80-100^{\circ} \mathrm{C}$ for $30 \mathrm{~min}$ and cooled in running water. An amount of $1.5 \mathrm{ml}$ of hexane was also added and the mixture 
was vortexed for 30 seconds. Lastly, $3.0 \mathrm{ml}$ of saturated $\mathrm{NaCl}$ was added, vortexed for $2 \mathrm{~min}$, and incubated or stored in the freezer until 2 layers were formed. The top layer was withdrawn and placed in a vial containing anhydrous $\mathrm{Na}_{2} \mathrm{SO}_{4}$ and then stored in the freezer prior to analysis.

The methylated samples were injected into gas chromatography. Fatty acids were identified by FID detector with SP 2380 capillary column. The process temperature conditions were $160-174^{\circ} \mathrm{C}$ with a rate of temperature increase of $2^{\circ} \mathrm{C} / \mathrm{min}$, followed by $174-190^{\circ} \mathrm{C}$ with a rate of increase in temperature of $1{ }^{\circ} \mathrm{C} / \mathrm{min}$. Other conditions are FID temperature of $250^{\circ} \mathrm{C}$ and gas helium (He) carrier with a pressure of 18 psi. The response generated is presented in the form of a chromatogram (peak) and the type of fatty acid was identified by comparing the chromatogram (peak) of standard fatty acids (lipid anchor: fatty acid methyl ester).

\section{Determination of amino acid composition}

Amino acid measurement was carried out using the UPLC instrument (Sitanggang et al., 2020a). The measurement was conducted by milling the sample into powder. The powdered sample was put in a vial and was added with pyrolyzed borosilicate. It was then hydrolysed with $5 \mathrm{~mL}$ of $6 \mathrm{~N} \mathrm{HCl}$ solution. The hydrolysis process was carried out at $110^{\circ} \mathrm{C}$ for 22 hours. The solution was cooled and diluted with aqua bidest until the calibration line of $50 \mathrm{~mL}$ volumetric flask was reached. Subsequently, the sample is filtered using a $0.45 \mu \mathrm{m}$ filter. An amount of $500 \mu \mathrm{L}$ of filtering result was added with $40 \mu \mathrm{m}$ of $\alpha$-amino butiric acid and $460 \mu \mathrm{L}$ of aqua bidest. As much as $10 \mu \mathrm{L}$ of the solution was taken and added with $70 \mu \mathrm{L}$ Acc QFluor and $20 \mu \mathrm{L}$ reagent fluor A. The UPLC operating conditions were: temperature of $49^{\circ} \mathrm{C}$, a flow rate of $0.7 \mathrm{~mL} / \mathrm{min}$, column type of ACC Q-Taq Ultra C18, PDA detector at wavelength $260 \mathrm{~nm}$, and injection volume is $1 \mathrm{uL}$.

\section{Determination of antioxidant properties}

The antioxidant properties determined in this study included analysis of total phenol, total flavonoids, $\gamma$-oryzanol, anthocyanin, and antioxidant activity $\left(\mathrm{IC}_{50}\right)$. The total phenol (TPC) analysis was carried out by extraction of $0.1 \mathrm{~g}$ sample, then added with $5 \mathrm{ml}$ of $95 \%$ ethanol. The solution was homogenized by means of vortex and finally centrifuged for $5 \mathrm{~min}$ at $4000 \mathrm{rpm}$. The supernatant obtained was used for the analysis of total phenol. The analysis started by the addition of $0.5 \mathrm{~mL}$ sample into a test tube containing $0.5 \mathrm{~mL}$ of $95 \%$ ethanol and $2.5 \mathrm{ml}$ of distilled water. The solution was then added with $0.5 \mathrm{~mL}$ of $50 \%$ Folin-Ciocalteau reagent. After leaving it for $5 \mathrm{~min}, 0.5 \mathrm{~mL}$ of $5 \% \mathrm{Na}_{2} \mathrm{CO}_{3}$ was added. The solution was homogenized and incubated for $60 \mathrm{~min}$ in a dark room. After that, the absorbance was monitored at a wavelength of $725 \mathrm{~nm}$ (Sitanggang et al., 2021).

The total flavonoids (TFC) were carried out by the colorimetric method. An amount of $100 \mathrm{mg}$ of methanol extract of the sample was dissolved in $100 \mathrm{~mL}$ of methanol. In a $10 \mathrm{~mL}$ volumetric flask, $1 \mathrm{~mL}$ of the sample solution was added and added with $0.2 \mathrm{~mL}$ of $\mathrm{AlCl}_{3} 10 \%, 3 \mathrm{~mL}$ methanol, and $0.2 \mathrm{~mL}$ of potassium acetate $1 \mathrm{M}$. The volume of the solution was adjusted to the calibration line with distilled water. The solution is then homogenized and incubated in a dark room for $30 \mathrm{~min}$ at room 
temperature. The absorbance of the solution was monitored by means of UV-VIS spectrophotometry with a wavelength of $431 \mathrm{~nm}$. In this study, the flavonoid content is considered equivalent to quercetin.

Determination of $\gamma$-oryzanol was carried out following partial extraction method (Lilitchan et al., 2008; Munarko et al., 2020). As much as $1.0 \mathrm{~g}$ samples were weighed twice, placed into two test tubes and extracted with isopropanol with different volumes ( 4 and $8 \mathrm{~mL}$ ) for $1 \mathrm{~min}$ at room temperature. The solutions were centrifuged at $3000 \mathrm{rpm}$ for $10 \mathrm{~min}$. The absorbance values were quantified at a wavelength of $326 \mathrm{~nm}$ by means of a UV-vis spectrophotometer. The concentration of $\gamma$-oryzanol were calculated as following (Equation 1):

$$
y=\frac{\mathrm{x} 1 \mathrm{x} 2}{2 \mathrm{x} 1-\mathrm{x} 2}
$$

where $\mathrm{x}_{1}$ and $\mathrm{x}_{2}$ were the amount (g) of $\gamma$-oryzanol in the extract with different isopropanol volumes, and y was the calculated amount of $\gamma$-oryzanol obtained in the glutinous rice.

Meanwhile, anthocyanin analysis was conducted by the differential $\mathrm{pH}$ method (Giusti and Wrolstad, 2001). A quantity of $0.05 \mathrm{~mL}$ of each sample of different $\mathrm{pH}$ was put into two test tubes. The first test tube was added with $4.95 \mathrm{~mL}$ potassium chloride buffer solution $(0.025 \mathrm{M})$ of $\mathrm{pH}=1$ and the second test tube was added with $4.95 \mathrm{~mL}$ sodium acetate buffer $(0.4 \mathrm{M})$ of $\mathrm{pH}=4.5$. The absorbance of the two $\mathrm{pH}$ treatments was measured by a spectrophotometer at a wavelength of $516 \mathrm{~nm}$ and 700 $\mathrm{nm}$ after leaving for $15 \mathrm{~min}$. The anthocyanin concentration was calculated as cyanidin-3-glycoside using a molar extension coefficient of $29.600 \mathrm{~L} / \mathrm{cm}$ and a molecular weight of $448.8 \mathrm{~g} / \mathrm{mol}$.

As for the determination of antioxidant activity, it was carried out using the DPPH (1,1-diphenyl-2-pikrilhidrazil) method. The principle of this method is that antioxidant compounds will react with DPPH radicals through the mechanism of donating hydrogen atoms and causing DPPH color reduction from purple to yellow. The active compound as an antioxidant will reduce DPPH free radicals to diphenyl picryl hydrazine (Sitanggang et al., 2020b).

\section{Statistical analysis}

The statistical analysis (analysis of variance/ANOVA) was performed using SPSS for Windows Version 22.0. If the mean differences existed, multiple comparisons were performed using the Duncan's Multiple Range Test (DMRT). All analysis was conducted using SPSS for Windows Version 22.0.

\section{Results and discussion}

\section{Determination of chemical composition}

The results of the chemical composition analysis and digestibility of the three glutinous rice cultivars from West Sumatra are presented in Table 1. The table shows 
that each glutinous rice cultivars from West Sumatera that were studied in the present research had significant differences in protein content, fat, and ash from one another. The highest protein content of $10.37 \%(\mathrm{db})$ was registered in red glutinous rice and the lowest protein was found in black glutinous rice $(9.00 \% \mathrm{db})$. The highest total fat content was registered for white glutinous rice $(3.11 \% \mathrm{db})$ and the lowest fat content was registered for black glutinous rice $(2.05 \% \mathrm{db})$. The highest total ash content had the black glutinous rice $(2.36 \%)$ and the lowest white glutinous rice $(0.99 \%)$. Additionally, the total fiber content in the three types of glutinous rice was significantly different including their soluble and insoluble fiber content. The dominant type of dietary fiber in these three glutinous cultivars was insoluble fiber (\% IDF).

Based on the information in Table 1, the results obtained in this study are in accordance with the results reported by Saleh et al. (2019) and Sompong et al. (2011). Saleh et al. (2019) have reported that brown rice (non-pigmented rice) contains $7.1-8.3 \%$ protein, $1.6-2.8 \%$ crude fat, $1.0-1.5 \%$ crude ash, and $0.6-1.0 \%$ crude fiber. Meanwhile, Sompong et al. (2011) reported that pigmented rice (red and black rice) contains $7.2-10.9 \%$ protein, $1.2-3.7 \%$ fat, $0.8-1.7 \%$ ash, $2.5-4.5 \%$ dietary fiber.

Table 1. Chemical composition and digestibility of three cultivars of Indonesian glutinous rice.

\begin{tabular}{|c|c|c|c|c|}
\hline No. & Parameters & $\begin{array}{l}\text { White } \\
\text { glutinous rice }\end{array}$ & $\begin{array}{l}\text { Red glutinous } \\
\text { rice }\end{array}$ & $\begin{array}{l}\text { Black } \\
\text { glutinous rice }\end{array}$ \\
\hline 1. & Moisture content $(\% \mathrm{db})$ & $18.03 \pm 0.38^{c}$ & $14.65 \pm 0.04^{\mathrm{b}}$ & $13.32 \pm 0.25^{\mathrm{a}}$ \\
\hline 2. & Ash (\% db) & $0.99 \pm 0.02^{\mathrm{a}}$ & $1.82 \pm 0.02^{b}$ & $2.36 \pm 0.03^{c}$ \\
\hline 3. & Crude fat $(\% \mathrm{db})$ & $3.11 \pm 0.06^{\mathrm{c}}$ & $2.40 \pm 0.03^{b}$ & $2.052 \pm 0.03^{\mathrm{a}}$ \\
\hline 4. & Crude protein $(\% \mathrm{db})$ & $9.87 \pm 0.06^{\mathrm{b}}$ & $10.37 \pm 0.11^{\mathrm{c}}$ & $9.00 \pm 0.05^{\mathrm{a}}$ \\
\hline 5. & Carbohydrate $(\% \mathrm{db})$ & $68.00 \pm 0.40^{\mathrm{a}}$ & $70.76 \pm 0.14^{\mathrm{b}}$ & $73.27 \pm 0.26^{\mathrm{c}}$ \\
\hline 6. & Amylose content (\%) & $5.62 \pm 0.14^{\mathrm{b}}$ & $5.06 \pm 0.25^{\mathrm{a}}$ & $4.73 \pm 0.05^{\mathrm{a}}$ \\
\hline 7. & $\begin{array}{l}\text { Amylopectin content } \\
(\%)\end{array}$ & $94.38 \pm 0.14^{\mathrm{a}}$ & $94.94 \pm 0.25^{\mathrm{b}}$ & $95.27 \pm 0.05^{\mathrm{b}}$ \\
\hline \multirow[t]{3}{*}{8.} & Total dietary fiber $(\%)$ & $3.21 \pm 0.18^{\mathrm{a}}$ & $6.27 \pm 0.06^{\mathrm{b}}$ & $6.54 \pm 0.09^{c}$ \\
\hline & $\begin{array}{l}\text { Soluble dietary fiber } \\
\text { (\% SDF) }\end{array}$ & $0.75 \pm 0.04^{\mathrm{a}}$ & $0.85 \pm 0.03^{b}$ & $0.94 \pm 0.04^{c}$ \\
\hline & $\begin{array}{l}\text { Insoluble dietary fiber } \\
\text { (\% IDF) }\end{array}$ & $2.46 \pm 0.16^{\mathrm{a}}$ & $5.41 \pm 0.08^{b}$ & $5.60 \pm 0.13^{b}$ \\
\hline 9. & Digestibility of starch (\%) & $96.38 \pm 0.44^{\mathrm{b}}$ & $96.02 \pm 0.17^{\mathrm{b}}$ & $94.42 \pm 0.17^{\mathrm{a}}$ \\
\hline
\end{tabular}

Different letters in the same row between corresponding pairs indicate significant differences $(\mathrm{p}<0.05)$ by Duncan's test.

In Table 1 it can be seen that white glutinous rice had the highest amylose content the lowest values were registered for black glutinous rice. However, the percentage is not significantly different with red glutinous rice. Since the amylose contents for those three rice cultivars were approximately $5 \%$, it can be concluded that three 
cultivars of glutinous rice from West Sumatra were typically waxy to low amylose content. The proportion of amylose to amylopectin in rice can impact the texture of cooked rice. The starch that contains a high quantity of amylopectin (low amylose content) will be difficult to form a firm gel when cooked and the resulting paste is softer (longer shape texture). The nature of the softer gel causes a tendency to stretch and break, resulting in a greater level of development. Therefore, before cooking glutinous rice, it is necessary to give soaking treatment at a certain time to increase the absorption of water so that the glutinous rice's water content is sufficient to carry out the gelatinization process during cooking or heating of starch. The higher the content of amylose the greater the ability of starch to absorb water because amylose has a greater ability to form hydrogen bonds than amylopectin (Suwannaporn et al., 2007; Kang et al., 2010).

Starch in rice belongs to the rapidly digestible starch (RDS) type, as well as potato starch. Table 1 shows that the digestibility of glutinous rice starch was high (94.42$96.38 \%)$. The highest values were registered for white glutinous rice $(96.38 \%)$ and the lowest for black glutinous rice $(94.42 \%)$. The rapidity of starch to be hydrolyzed is related to its dietary fiber composition. Dietary fiber cannot be digested and absorbed by the intestine but has a very important function for health maintenance and prevention of various diseases. Soluble dietary fiber (SDF) functions to slow down the speed of digestion in the intestine, therefore providing a longer feeling of satiety. SDF also slows down the appearance of blood glucose so that insulin transfers glucose into the cells of the body and is converted into less energy. Whereas, insoluble dietary fiber (IDF) functions to prevent various diseases related to the intestine, diverticulosis, and colon cancer. Rice with high dietary fiber (especially SDF) will reduce the speed of starch digestion in the intestine. The results of this study indicate that black glutinous rice has the highest total dietary fiber and soluble dietary fiber compared to white glutinous rice and red glutinous rice. It also has slower starch hydrolysis (digestibility) than white glutinous rice and red glutinous rice. This shows that total dietary fiber and soluble dietary fiber are positively correlated with the decreasing digestion rate of starch.

\section{Pasting properties of glutinous rice}

Each type of starch has a unique pasting property. Factors that affect the pasting properties include the source of starch, the size of starch granules, the presence of dissolved components (acids, sugars, fats, proteins, and enzymes), cooking temperatures, and stirring or agitation processes (Suwannaporn et al., 2007).

Kang et al. (2010) reported that glutinous rice varieties tend to exhibit lower pasting temperatures compared to non-glutinous rice. In this study, the pasting properties of each glutinous rice sample are slightly different. Figure 1 shows that white glutinous rice has the highest maximum viscosity value compared to red glutinous rice and black glutinous rice, but the viscosity in the cooling phase is higher than that of red glutinous rice and black glutinous rice. This is because white glutinous rice contains higher amylose than red dan black glutinous rice (Table 1). Suwannaporn et al. (2007) explained that starch containing higher amylose tends to give a greater setback viscosity. The starch that has a higher amylose content can be used as a gel- 
forming or film-forming because it is easier to form hydrogen bonds when the starch paste is produced and it affects the strength of the gel texture in the product produced. Whereas starch with a lower amylose content (high amylopectin) will give a thicker and stickier paste texture that is suitable to use as a thickener. Moreover, starch high in amylose content will be more susceptible to syneresis due to starch retrogradation, especially during cold storage. From the results of this study, white glutinous rice is more suitable to use as a gel-forming than red and black glutinous rice. While black glutinous rice is more recommended to use as a thickener and frozen food products or food products that must be stored at low temperatures compared to white glutinous rice and red glutinous rice.

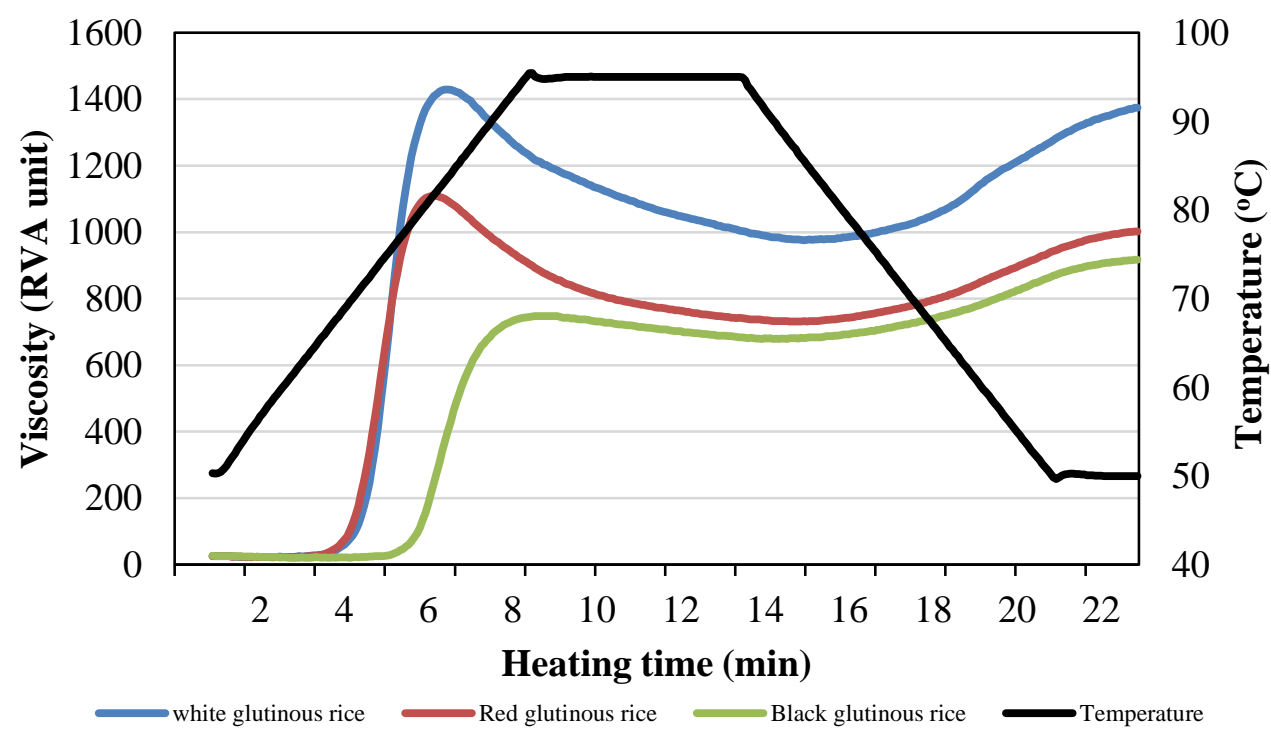

Figure 1. Pasting properties of three cultivars of Indonesian glutinous rice.

The pasting temperature of black glutinous rice starch $\left(79.35^{\circ} \mathrm{C}\right)$ was higher than white glutinous rice $\left(70.4^{\circ} \mathrm{C}\right)$ and red glutinous rice $\left(69.25^{\circ} \mathrm{C}\right)$. Profile of pasting properties in black glutinous rice was also gentler than white glutinous rice and red glutinous rice. This is related to the fat, protein, and simple sugars contained in each glutinous rice. The presence of fat and protein in food can form a layer on the surface of starch granules that causes a delay in the starch gelatinization process because it inhibits water adsorption. The process of delaying gelatinization can be observed from the increase in pasting temperature and sloping gelatinization profile of starch. Additionally, the presence of simple sugars (a constituent component of carbohydrates) enables to bind of some of the water in the starch suspension. The more the amount of simple sugar contained in a food, the slower the pasting process of the starch will be. 


\section{The microstructure of glutinous rice starch}

Rice is one of the cereals that are rich in starch. Starches composed of amylose and amylopectin are stored in the endosperm of rice in the form of white granules, shiny, odorless, and tasteless. Together with the ratio of amylose and amylopectin, shape and size of starch granules are also different from different food sources. The observation of morphological (shape and size) 3D images of starch granules on the surface was carried out with the use of a scanning electron microscope (SEM). The scanning electron microscope of the glutinous rice granules is shown in Figure 2. The morphological images of starch granules from the three glutinous rice cultivars are relatively different from each other but in general, they have polyhedral and irregular-shaped granules. This results are in agreement with Kang et al. (2010) who reported that rice starch granules are polyhedral and in different sizes but mostly composed of large polyhedral granules with a few small and irregular-shaped granules. The structure (shape and size) of starch granules is closely related to the gelatinization properties of the starch.

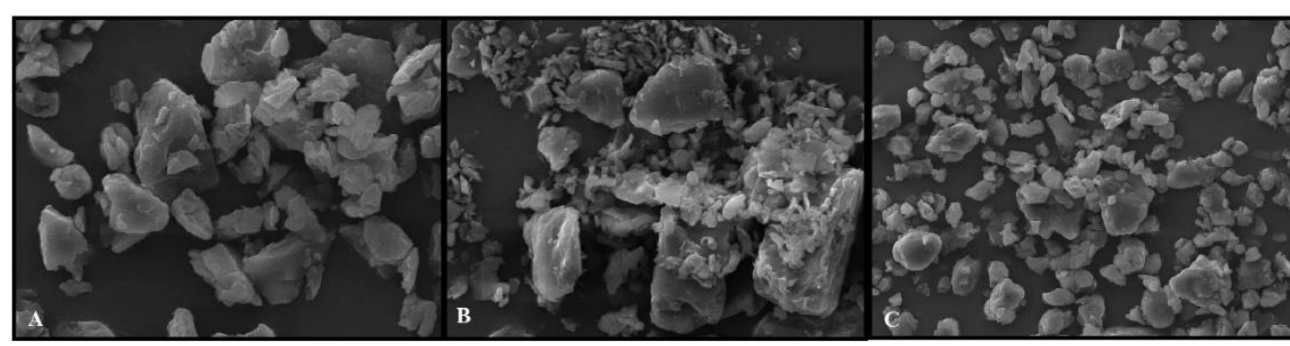

Figure 2. Microstructures of three cultivars of Indonesian glutinous rice starches (magnification: 1000x): (A) white glutinous rice, (B) red glutinous rice, (C) black glutinous rice.

\section{Determination of fatty acids composition}

The presence of fatty acids in food matrix normally has health impact. In general, the fatty acids can be classified into saturated fatty acids (SFAs) and unsaturated fatty acids (UFAs). For the latter, they can be grouped as mono (MUFAs) and polyunsaturated fatty acids/PUFAs (Orsavova et al., 2015). Rice has been reported to contain amino acids, essential fatty acids, and other bioactive compounds (Gines et al., 2016). The composition of fatty acids of the three types of samples used in this research is presented in Table 2 . The saturated fatty acids found in glutinous rice are medium (C14) up to long carbon saturated fatty acids (C22). The highest total saturated fatty acids are black glutinous rice and the lowest is in red glutinous rice. While the highest total of unsaturated fatty acid is red glutinous rice and the lowest is black glutinous rice. The highest type of saturated fatty acid found in glutinous rice is palmitic acid while the highest unsaturated fatty acid type is linoleic acid, followed by oleic acid. Kang et al., (2010) and Kita et al. (2005) reported that the major fatty acids in Korean glutinous rice and Japanese glutinous rice are palmitic acid for saturated fatty acid, and oleic and linoleic acid for unsaturated fatty acids. 
Furthermore, Valantina et al. (2010) and Gines et al. (2016) reported that saturated fatty acids were about $21-25 \%$ of palmitic acid and $2.7-3.0 \%$ of stearic acid. While unsaturated fatty acids were about $75 \%(\mathrm{w} / \mathrm{w})$, composed of oleic $(36-38 \%)$, linoleic (35-38\%), and $\alpha$-linolenic (1.8-2.4\%). In agreement with previous studies, the major saturated fatty acid found in glutinous rice (white, red and black) was palmitic acid, approximately $20 \%$. For unsaturated fatty acids were also in similar contents with previous literature which composed of oleic and linoleic acid.

Table 2. Fatty acid composition of three cultivars of Indonesian glutinous rice.

\begin{tabular}{|c|c|c|c|c|c|}
\hline No. & Fatty acids & $\begin{array}{l}\text { FA } \\
\text { Shorthand }\end{array}$ & $\begin{array}{l}\text { White } \\
\text { glutinous } \\
\text { rice }\end{array}$ & $\begin{array}{l}\text { Red } \\
\text { glutinous } \\
\text { rice } \\
\end{array}$ & $\begin{array}{l}\text { Black } \\
\text { glutinous } \\
\text { rice }\end{array}$ \\
\hline \multicolumn{6}{|c|}{ Saturated fatty acids } \\
\hline 1 & Myristic acid (\%) & C14:0 & 0.618 & 0.310 & 0.337 \\
\hline 2 & Palmitic acid (\%) & C16:0 & 20.947 & 20.305 & 20.629 \\
\hline 3 & Stearic acid $(\%)$ & C18:0 & 1.598 & 2.226 & 2.110 \\
\hline 4 & $\begin{array}{l}\text { Arachidic acid } \\
(\%)\end{array}$ & C20:0 & 0.671 & 0.759 & 0.729 \\
\hline 5 & Behenic acid (\%) & $\mathrm{C} 22: 0$ & 0.345 & 0.422 & 0.389 \\
\hline 6 & Lignocerat (\%) & $\mathrm{C} 24: 0$ & 0.579 & 0.651 & 0.798 \\
\hline Tota & $(\%)$ of saturated & tty acids & 24.757 & 24.672 & 24.993 \\
\hline \multicolumn{6}{|c|}{ Unsaturated fatty acids } \\
\hline 1 & $\begin{array}{l}\text { Palmitoleic acid } \\
(\%)\end{array}$ & C16:1 & 0.095 & ND & 0.131 \\
\hline 2 & Oleic acid (\%) & C18:1 & 36.482 & 34.735 & 34.166 \\
\hline 3 & Linoleic acid (\%) & C18:2 & 36.942 & 37.859 & 38.524 \\
\hline 4 & $\begin{array}{l}\text { Linolenic acid } \\
(\%)\end{array}$ & $\mathrm{C} 18: 3$ & 1.371 & 2.428 & 1.747 \\
\hline 5 & $\begin{array}{l}\text { Eicosanoic Acid } \\
(\%)\end{array}$ & C20:1 & 0.358 & 0.305 & 0.443 \\
\hline \multicolumn{3}{|c|}{$\begin{array}{l}\text { Monounsaturated fatty acids (MUFAs) } \\
(\%)\end{array}$} & 36.94 & 35.04 & 34.74 \\
\hline \multicolumn{3}{|c|}{$\begin{array}{l}\text { Poliunsaturated fatty acids (PUFAs) } \\
(\%)\end{array}$} & 38.31 & 40.29 & 40.27 \\
\hline \multicolumn{3}{|c|}{ Total (\%) of unsaturated fatty acids } & 75.250 & 75.328 & 75.013 \\
\hline
\end{tabular}

$\mathrm{ND}=$ not detected

The source of the oil consequently defines the type and composition of fatty acids. The proportion of fatty acids strongly influence the physical, chemical, and physiological properties of lipids. The presence of SFAs in oil is both advantageous and disadvantageous. High levels of SFAs can be beneficial to improve oil stability during its applications for processing foods. The presence of SFAs can increase the oil melting point, resulting in a solid phase oil at room temperature. However, SFAs can also contribute to the increase of low-density lipoprotein (LDL) proportion which may lead to clothing (Orsavova et al., 2015). 
The presence of high levels of unsaturated fatty acids in edible oil may increase their susceptibility to oxidation, thus, reducing fat/oil quality. This oxidation reaction triggers the formation of volatile primary, secondary, and tertiary products. Consequently, fat or high fat-containing food becomes rancid and less preferred for consumption. Lipid damage will easily occur because of the increase in the rate of oxidation reactions caused by an increase in unsaturated fatty acid content that involves double bonds in the carbon chain (Orsavova et al., 2015).

Table 2 shows that PUFAs was higher than MUFAs content in each type of glutinous rice from West Sumatera. Besides having anti-thrombotic properties and improving insulin sensitivity, MUFAs has been reported to increase HDL/LDL ratio that is beneficial to control blood pressure. Red glutinous rice had the highest PUFAs content, whereas the lowest one owned by white glutinous rice. The nomenclature of essential fatty acids (EFAs) depends on the position of the first double bond from the fatty acid methyl-end. Herein, linoleic acid and linolenic acid are considered as omega-6 (n6) and omega-3 (n-3), respectively. EFAs are those fatty acids that the body cannot synthesize, thus they are obtained through food consumption (diet). The presence of EFAs can increase biological activity as well as improve nutraceutical properties of the food products. The $\alpha$-linolenic and linoleic acid are considered as fundamental PUFAs/EFAs since other important PUFAs can be derived from these acids. The levels of PUFAs in an edible oil, especially $n-6 / n-3$ ratio may help to evaluate nutritional quality of rice cultivars in this study, especially the oil contribution to HDL/LDL ratio (Lawton et al., 2000). Additionally, linoleic acid is reported to play role in the biosynthesis of prostaglandins and many cellular processes (Gines et al., 2016). Several health significances of these MUFAs/PUFAs/EFAs are as antiatherogenic, antithrombotic, anti-inflammatory, antiarrhythmic, hypolipidemic effect, reducing the possibility of cardiovascular diseases, cancer, osteoporosis, and diabetes (Luque-Rodríguez et al., 2005; Yi et al., 2009; Orsavova et al., 2015;). The results of the fatty acid analysis also indicate that the three types of glutinous rice have the potential as a functional food because it is rich in MUFA and PUFA.

\section{Determination of amino acids composition}

Based on the results of this study it was found that the total amino acid component was $87237.94 \mathrm{mg} / \mathrm{kg}$ sample in red glutinous rice, $78739.06 \mathrm{mg} / \mathrm{kg}$ sample in white glutinous rice, and $74532.59 \mathrm{mg} / \mathrm{kg}$ sample in black glutinous rice. Figure 3 shows that the composition of each of the highest amino acids was in red glutinous rice, except that methionine was mostly found in white glutinous rice. The highest amino acid component in the three types of glutinous rice was glutamate acid, leucine, and arginine. The highest glutamate acid content was in red glutinous rice, which was $14848.10 \mathrm{mg} / \mathrm{kg}(16.48 \%)$, then white glutinous rice amounted to $12976.48 \mathrm{mg} / \mathrm{kg}$ (17.02\%), and black glutinous rice amounted to $12765.39 \mathrm{mg} / \mathrm{kg}$ sample (17.13\%). The leucine content was $7777.24 \mathrm{mg} / \mathrm{kg}$ sample $(8.91 \%)$ in red glutinous rice, $6323.47 \mathrm{mg} / \mathrm{kg}$ sample in white glutinous rice, and $6425.54 \mathrm{mg} / \mathrm{kg}$ sample $(8.62 \%)$ in black glutinous rice. The arginine content was $7669.89 \mathrm{mg} / \mathrm{kg}$ sample $(8.79 \%)$ in red glutinous rice, $6883.36 \mathrm{mg} / \mathrm{kg}$ sample $(8.74 \%)$ in white glutinous rice, and 
$6435.23 \mathrm{mg} / \mathrm{kg}$ sample (8.64\%) in black glutinous rice. On the other hand, the lowest amino acid composition of the three varieties was different, where the lowest amount of amino acid in white glutinous varieties was tryptophan (388.24 mg/kg sample), while in red glutinous rice was methionine $(251.57 \mathrm{mg} / \mathrm{kg}$ sample), and in black rice was cysteine $(378.14 \mathrm{mg} / \mathrm{kg}$ sample). This is slightly different from the dominant amino acid composition in the local Korean glutinous rice variety, namely white glutinous rice. Kang et al. (2010) reported that the dominant amino acids in local Korean glutinous rice were glutamate, asparagine, and aspartate. While the smallest amino acid was tryptophan.

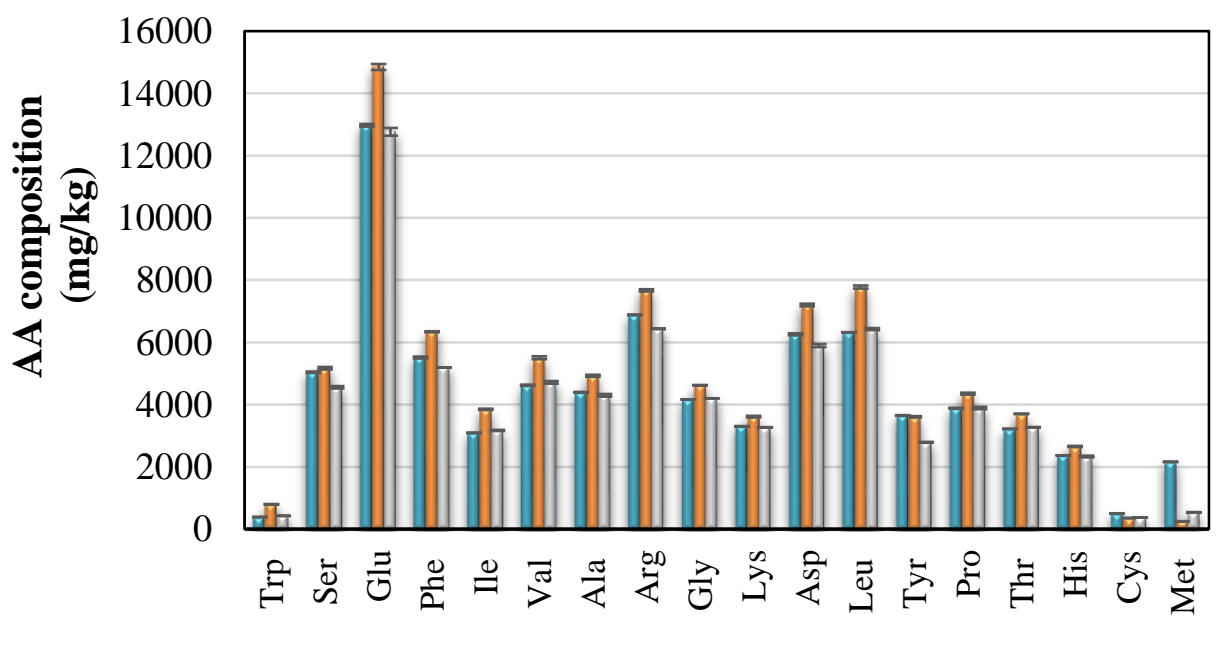

$\square$ White Glutinous rice $\square$ Red Glutinous Rice $\square$ Black Glutinous Rice

Figure 3. Amino acid (AA) composition of three cultivars of Indonesian glutinous rice.

The quality of a protein is assessed from the composition of amino acids contained in the proteins. Proteins that are rich in essential amino acids are considered to have good quality (Amagliani et al., 2017). Figure 3 also shows that the three types of glutinous rice contained all types of essential amino acids needed by the body, especially for Arginine (Arg). Arg is an essential component of dietary protein since it has important roles on the reproduction, fetal and postnatal development as well as positive impacts on the treatment of obesity, diabetes, and metabolic syndrome (Wu et al., 2009). The requirement of an average daily intake of Arg is 2.5-5 g/day. Besides Arg, another important essential amino acid is lysine (Lys). Lys is often used as an indicator of food quality degradation because it is easier to engage in the Maillard reaction (Yang et al., 2016). Figure 3 also shows that the three types of glutinous rice also have a fairly high lysine content of around $4 \%$ (black glutinous rice $4.38 \mathrm{mg} / \mathrm{kg}$, white glutinous rice $4.20 \mathrm{mg} / \mathrm{kg}$, and red glutinous rice at $4.14 \%$ ). Free amino acids contribute to the flavor characteristics of foods. L-Glutamate (Glu), especially if it is in the form of Na-glutamate, is a non-essential amino acid that can 
provide a high-intensity savory (umami) flavor to food. The contribution of amino acids to flavor is also influenced by the polarity and structure or configuration ( $\mathrm{L}$ or D) of the amino acid (Dajanta et al., 2011). This research shows that red glutinous rice contains higher Glu than white glutinous rice and black glutinous rice. This data explains that brown rice has a stronger umami taste than white glutinous rice and black glutinous rice.

\section{Antioxidant properties}

Antioxidant activity is influenced by the synergistic interactions of all its bioactive compounds or antioxidant compounds. The antioxidant compounds in rice are classified into six groups, such as phenolic acids, flavonoids anthocyanins and proanthocyanidins, tocopherols, and tocotrienols (vitamins E), $\gamma$-oryzanol, and phytic acid (Goufo and Trindade, 2014). Table 3 shows that the highest antioxidant activity with IC 50 assay is black glutinous rice. This is in synergy with the results of antioxidant compounds measurements obtained in this research, where almost all of the antioxidant components in this glutinous rice are higher than the other types of glutinous rice used in this research.

Table 3. Compound exhibiting antioxidant properties and antioxidant $\mathrm{IC}_{50}$ of three cultivars of Indonesian glutinous rice.

\begin{tabular}{|c|c|c|c|c|}
\hline No. & Parameters (\% db) & $\begin{array}{l}\text { White } \\
\text { glutinous rice }\end{array}$ & $\begin{array}{l}\text { Red glutinous } \\
\text { rice }\end{array}$ & $\begin{array}{l}\text { Black } \\
\text { glutinous } \\
\text { rice }\end{array}$ \\
\hline 1. & $\begin{array}{l}\text { Total phenolic acid } \\
\text { (mg GAE/g) }\end{array}$ & $0.66 \pm 0.04^{\mathrm{a}}$ & $0.76 \pm 0.04^{\mathrm{b}}$ & $1.210 \pm 0.02^{\mathrm{c}}$ \\
\hline 2. & $\begin{array}{l}\text { Total flavonoids } \\
\text { (mg quercetin/g) }\end{array}$ & $2.69 \pm 0.13^{\mathrm{a}}$ & $3.02 \pm 0.25^{\mathrm{ab}}$ & $3.19 \pm 0.10^{\mathrm{b}}$ \\
\hline 3. & $\gamma$-Oryzanol $(\mathrm{mg} / \mathrm{g})$ & $0.642 \pm 0.01^{\mathrm{a}}$ & $0.674 \pm 0.01^{\mathrm{a}}$ & $1.336 \pm 0.03^{b}$ \\
\hline 4. & Anthocyanin (mg CyE/g) & $0.004 \pm 0.002^{\mathrm{a}}$ & $0.69 \pm 0.04^{\mathrm{b}}$ & $2.40 \pm 0.04^{\mathrm{c}}$ \\
\hline 5. & $\begin{array}{l}\text { Antioxidant activity }\left(\mathrm{IC}_{50}\right) \\
(\mathrm{ppm})\end{array}$ & $764.52 \pm 1.07^{\mathrm{b}}$ & $109.40 \pm 0.14^{\mathrm{a}}$ & $44.97 \pm 0.08^{a}$ \\
\hline
\end{tabular}

Different letters in the same row between corresponding pairs indicate significant difference $(\mathrm{p}<0.05)$ by Duncan's test.

The total phenolic acid and anthocyanin content of each cultivar were significantly different, while the $\gamma$-oryzanol content between white glutinous rice and red glutinous rice is not significantly different. This result is consistent with that reported by Shao and Bao (2015) in which black rice and brown rice have much higher total phenol content than white rice. Different varieties and growing areas of rice will produce rice bran with different levels of bioactive components, the same goes with glutinous rice. Furthermore, Goufo and Trindade (2014) reported that whole grain rice contains total phenolic acid of $263.9 \mathrm{mg} \mathrm{GAE} / 100 \mathrm{~g}$ (non-pigmented rice) and $500.3 \mathrm{mg} \mathrm{GAE} / 100 \mathrm{~g}$ (pigmented rice), total flavonoid compounds of $188.4 \mathrm{mg}$ catechin equivalent/100 g (non-pigmented rice) and $330.9 \mathrm{mg}$ catechin equivalent $/ 100 \mathrm{~g}$ (pigmented rice), $\gamma$-oryzanol content of $413.3 \mathrm{mg} / \mathrm{kg} \mathrm{DW}$ (non- 
pigmented rice) and $474.3 \mathrm{mg} / \mathrm{kg} \mathrm{DW}$ (pigmented rice), total anthocyanins content of $2.00-3.26 \mathrm{mg} / 100 \mathrm{~g}$ (non-pigmented rice) and $4.1-256.5 \mathrm{mg} / 100 \mathrm{~g}$ (pigmented rice).

Antioxidants are reported to have functional properties that have a positive influence on health such as anticancer, antihypocholesterolemic, and antiatherogenic as well as reducing the possibility of harmful metabolic products (Laokuldilok et al., 2011; Sompong et al., 2011; Goufo and Trindade, 2014; Thammapat et al., 2015). Pigmented rice varieties possess higher antioxidant activities compared with nonpigmented rice varieties and have good ability or activity to capture free radicals. This is also seen in glutinous rice, where the pigmented glutinous rice has higher antioxidant activity compared to non-pigmented glutinous rice. Among the four types of rice ranked by color, black rice varieties emerged as those that exhibit the highest antioxidant activities, followed by purple, red, and brown rice varieties.

\section{Conclusions}

The physico-chemical and functional properties of several Indonesian rice cultivars (white, red and black glutinous rice) are characterized in this study. Each of these cultivars has different characteristics. Certainly, these differences will affect their applications as food ingredients and the final characteristics of the food products. This research shows that pigmented glutinous rice cultivars (red and black glutinous rice) have enormous potentials as functional food ingredients, due to their high contents of antioxidant compounds such as phenolic, flavonoids, $\gamma$-oryzanol, and anthocyanins. Additionally, all cultivars of glutinous rice are also rich in dietary fiber, essential amino acids, and essential fatty acids which previously have been reported to have physiological functions for the health of the human body.

\section{Acknowledgments}

The Education Fund Management Institution (LPDP), the Ministry of Finance, Republic of Indonesia with a Budi-DN 2016 Dissertation Grant Scheme was acknowledged to support this study.

\section{References}

Amagliani, L., O’Regan, J., Kelly, A.L., O’Mahony, J.A. 2017. The composition, extraction, functionality and applications of rice proteins: A review. Trends in Food Science and Technology, 64, 1-12.

American Association of Cereal Chemist (AACC). 2009. AACC Approved Methods of Analysis. $11^{\text {th }}$ ed. AACC 32-21.01; AACC 61-02.01. St.Paul, MN, USA.

Association of Official Analytical Chemists (AOAC). 2005. Official Methods of Analysis of AOAC International. AOAC 920.39C; AOAC 923.03; AOAC 925.09B; AOAC 992.23. Washington DC, USA.

Chavan, P., Sharma, S.R., Mittal, T.C., Mahajan, G., Gupta, S.K. 2017. Optimization of parboiling parameters to improve the quality characteristics of pusa basmati 1509 . Journal of Food Process Engineering, 40(3), e12454. 
Dajanta, K., Apichartsrangkoon, A., Chukeatirote, E., Frazier, R.A. 2011. Free-amino acid profiles of thua nao, a Thai fermented soybean. Food Chemistry, 125(2), 342-347.

Gines, B., Gray, J., Abugri, D. 2016. Preliminary comparison of fatty acid composition(s) of selected commercial rice brands commonly consumed in North America. Austin Journal of Nutrition and Food Sciences, 4(1), 1-5.

Giusti, M.M., Wrolstad, R.E. 2001. Characterization and measurement of anthocyanins by UV-Visible spectroscopy. Current Protocols in Food Analytical Chemistry, F1.2.1F1.2.13, 1-13.

Goufo, P., Trindade, H. 2014. Rice antioxidants: Phenolic acids, flavonoids, anthocyanins, proanthocyanidins, tocopherols, tocotrienols, $\gamma$-oryzanol, and phytic acid. Food Science and Nutrition, 2(2), 75-104.

Huang, Y., Lai, H. 2016. Bioactive compounds and antioxidative activity of colored rice bran. Journal of Food and Drug Analysis, 24(1), 564-574.

Juliano, B.O. 1971. A simplified assay for milled-rice amylose. Cereal Foods World, 16 (10), 334-360.

Kang, M.Y., Rico, C., Lee, S.C. 2010. Physicochemical properties of eight popular glutinous rice varieties in Korea. Plant Production Science, 13(2), 177-184.

Kita, K., Nakajima, S., Nakagawa, J. 2005. Dietary L-carnitine supplementation improves albumen quality of laying hens. Journal of Poultry Science, 42, 79-83.

Laokuldilok, T., Shoemaker, C.F., Jongkaewwattana, S., Tulyathan, V. 2011. Antioxidants and antioxidant activity of several pigmented rice brans. Journal of Agricultural and Food Chemistry, 59(1), 193-199.

Lawton, C.L., Delargy, H.J., Brockman, J., Smith, F.C., Blundell, J.E. 2000. The degree of saturation of fatty acids influences post-ingestive satiety. British Journal of Nutrition, $\mathbf{8 3}$, $473-482$.

Lilitchan, S., Tangprawat, C., Aryusuk, K., Krisnangkura, S., Chokmoh, S., Krisnangkura, K. 2008. Partial extraction method for the rapid analysis of total lipids and $\gamma$-oryzanol contents in rice bran. Food Chemistry, 106, 752-759.

Luque-Rodríguez, J., De Castro, M., Perez-Juan, P. 2005. Extraction of fatty acids from grape seed by superheated hexane. Talanta, 68(1), 126-130.

Munarko, H., Sitanggang, A.B., Kusnandar, F., Budijanto, S. 2020. Phytochemical, fatty acid and proximal composition of six selected Indonesian brown rice varieties. CYTA - Journal of Food, 18(1), 336-343.

Orsavova, J., Misurcova, L., Ambrozova, J.V., Vicha, R., Mlcek, J. 2015. Fatty acids composition of vegetable oils and its contribution to dietary energy intake and dependence of cardiovascular mortality on dietary intake of fatty acids. International Journal of Molecular Sciences, 16(12), 12871-12890.

Saleh, A.S.M., Wang, P., Wang, N., Yang, L., Xiao, Z. 2019. Brown rice versus white rice: Nutritional quality, potential health benefits, development of food products, and preservation technologies. Comprehensive Reviews in Food Science and Food Safety, 18, 1070-1096.

Shao, Y., Bao, J. 2015. Polyphenols in whole rice grain: Genetic diversity and health benefits. Food Chemistry, 180, 86-97.

Sitanggang, A.B., Lesmana, M., Budijanto, S. 2020a. Membrane-based preparative methods and bioactivities mapping of tempe-based peptides. Food Chemistry, 329, 127193. 
Sitanggang, A.B., Sinaga, W.S.L., Wie, F., Fernando, F., Krusong, W. 2020b. Enhanced antioxidant activity of okara through solid state fermentation of GRAS fungi. Food Science and Technology, 40(1), 178-186.

Sitanggang, A. B., Sumitra, J., Budijanto, S. 2021. Continuous production of tempe-based bioactive peptides using an automated enzymatic membrane reactor. Innovative Food Science and Emerging Technologies, 68, 102639.

Sompong, R., Siebenhandl-Ehn, S., Linsberger-Martin, G., Berghofer, E. 2011. Physicochemical and antioxidative properties of red and black rice varieties from Thailand, China and Sri Lanka. Food Chemistry, 124, 132-140.

Suwannaporn, P., Pitiphunpong, S., Champangern, S. 2007. Classification of rice amylose content by discriminant analysis of physicochemical properties. Starch/Staerke, 59(3-4), $171-177$.

Thammapat, P., Meeso, N., Siriamornpun, S. 2015. Effects of $\mathrm{NaCl}$ and soaking temperature on the phenolic compounds, $\alpha$-tocopherol, $\gamma$-oryzanol and fatty acids of glutinous rice. Food Chemistry, 175, 218-224.

Valantina, S.R., Sahayaraj, P.A., Prema, A.A. 2010. Antioxidant stability in palm and rice bran oil using simple parameters. Rasāyan Journal, 3(1), 44-50.

Wu, G., Bazer, F.W., Davis, T.A., Kim, S.W., Li, P., Rhoads, J.M., Satterfield, M.C., Smith, S.B., Spencer, T.E., Yin, Y. 2009. Arginine metabolism and nutrition in growth, health and disease. Amino Acids, 37(1), 153-168.

Yang, Q.Q., Zhang, C.Q., Chan, M.L., Zhao, D.S., Chen, J.Z., Wang, Q., Li, Q.F., Yu, H.X., Gu, M.H., Sun, S.S.M., Liu, Q.Q. 2016. Biofortification of rice with the essential amino acid lysine: Molecular characterization, nutritional evaluation, and field performance. Journal of Experimental Botany, 67(14), 4285-4296.

Yi, C., Shi, J., Kramer, J., Xue, S., Jiang, Y., Zhang, M., Ma, Y., Pohorly, J. 2009. Fatty acid composition and phenolic antioxidants of winemaking pomace powder. Food Chemistry, 114(2), 570-576. 